Article

\title{
Evaluation of Driver Behavior Criteria for Evolution of Sustainable Traffic Safety
}

\author{
Danish Farooq *, Sarbast Moslem $₫$ and Szabolcs Duleba® \\ Department of Transport Technology and Economics, Budapest University of Technology and Economics, \\ Stoczek u. 2, H-1111 Budapest, Hungary; moslem.sarbast@mail.bme.hu (S.M.); \\ duleba.szabolcs@mail.bme.hu (S.D.) \\ * Correspondence: farooq.danish@mail.bme.hu
}

Received: 5 May 2019; Accepted: 30 May 2019; Published: 4 June 2019

\begin{abstract}
Driver behavior has been considered as the most influential factor in reducing fatal road accidents and the resulting injuries. Thus, it is important to focus on the significance of driver behavior criteria to solve road safety issues for a sustainable traffic system. The recent study aims to enumerate the most significant driver behavior factors which have a critical impact on road safety. The well-proven Analytic Hierarchy Process (AHP) has been applied for 20 examined driver behavior factors in a three-level hierarchical structure. Linguistic judgment data have been collected from three nominated evaluator groups in order to detect the difference of responses on perceived road safety issues. The comparison scales had been averaged prior to computing the weights of driver behavior factors. The AHP ranking results have revealed that most of the drivers are most concerned about the "Errors", followed by the "Lapses" for the first level. The highest influential sub-criteria for the second level is the "Aggressive violations" and for the third level, the "Drive with alcohol use". Kendall's rank correlation has also been applied to detect the agreement degree among the evaluator groups for each level in the hierarchical structure. The estimated results indicate that road management authorities should focus on high-rank significant driver behavior criteria to solve road safety issues for sustainable traffic safety.
\end{abstract}

Keywords: driver behavior; Analytic Hierarchy Process (AHP); ranking; Kendall's rank correlation; sustainable traffic safety

\section{Introduction}

More than 1.25 million people die each year as a result of road traffic crashes [1]. European roads have been observed as the safest in the world with a $19 \%$ decrease in road fatalities over the last six years. While achieving the strategic target of halving the number of road deaths between 2010 and 2020, which is still an extreme challenge, it is worth trying to save every single life [2]. The Road Safety Action Program (2014-2016) was integrated into the Hungarian Transport Strategy which also sets targets to reduce the number of road fatalities by 50\% between 2010 and 2020 [3]. However, according to Hungarian Central Statistical office data, there were 625 road fatalities in 2017, a 2.9\% rise when compared to 2016 [4].

The situation analysis of the Road Safety Action Program observes that most of the accidents are caused by human factors, therefore influencing them becomes the most important goal of road safety actions [3]. The NHTSA's 2008 [5] report specified that human error is the critical reason for 93\% of crashes.

In the scientific literature, most commonly the Driver Behavior Questionnaire (DBQ) has been used as a tool for examining the drivers to rate the significance of risk-elevating behaviors committed while driving. The Driver Behaviour Questionnaire (DBQ) was developed by Reason et al. [6] and 
refined by Parker et al. [7]. A structure comprised of slips/lapses, errors, ordinary violations, and aggressive violations has been broadly simulated, although the distinction between ordinary and aggressive violations is not always obtained at the factor or component level. Overall, the original three or four-factor (errors, lapses, aggressive and ordinary violations) structure has been broadly replicated in studies conducted in the UK [8-11].

Human behavior is considered as the most critical factor that affects road safety. Driver behavior identification and categorization plays a key role to reduce fatal road accidents and injuries [12,13]. Driving on urban roads requires full attention because of the complex driving operations that need a critical decision-making process in order to identify the risk factors for road safety. Most of the papers in the scientific literature in this area focused on statistical analysis based on driver response data, such as Refs. [14-17], but these papers lack a study regarding the decision of the most significant driver behavior criteria affecting road safety. The current study examined the important driver behavior factors affecting road safety through Analytic Hierarchy Process (AHP) to assist drivers for safe movements on the roads and to improve the sustainable level of traffic safety. AHP's application has been utilized very little in the traffic safety approach. Therefore, we applied the AHP method to identify and prioritize the most significant driver behavior factors to solve road safety issues. The Analytic Hierarchy Process (AHP) is the most useful technique to solve complex problems [18] like critical driver behavior evaluation among different evaluator groups from different perspectives.

The novelty of this paper is that an MCDM methodology, the Analytic Hierarchy Process, has been applied, thus the problem is considered as a decision support case using expert knowledge and preferences. The present study demonstrates an integrated model to highlight the most critical driver behavior factors related to road safety; the presented model is comprised of the Analytical Hierarchy Process (AHP) method along with Kendall's coefficient of concordance correlation. To better understand the significance of the driver behavior for sustainable traffic safety, the study analyzed 20 hypothetical most critical factors. A comprehensive AHP approach was employed to assign weights to each examined factor and enumerate the relative importance of each factor. For aggregation, the geometric mean technique was conducted to get a general assessment for all groups on perceived road issues. Further, Kendall's coefficient of concordance was employed to estimate the agreement degree among evaluator groups for each level. The study recommends that the high ranked risky driver behavior factors should be more focused to solve road safety issues.

\section{Driver Behavior Criteria}

Human factors have the most considerable impact on accident risk. Several studies focused on the fundamental factors solely related to road safety [19]. Many researchers and practitioners proved that the deviant behavior of a road user that differs from normal practices increases the risk of traffic crashes [20]. The aim of our paper is to signify the most critical driver behavior factors related to road safety.

The current research structured the significant driver behavior items into three levels in the designed hierarchical model. The first level included three main driver behavior criteria such as "Lapses", "Violations" and "Errors". The second level involved the distribution of these main driver behavior criteria into the related sub-criteria. Subsequently, the third level accessed the further distribution of two sub-criteria such as ordinary and aggressive violations into relevant sub-criteria. For the commencement of the study, the following hierarchical structure was created by the authors as shown in Figure 1.

Participants were asked to indicate how often they committed each of the examined driver behaviors in the previous year using Saaty's traditional ratio scale (1-9). A summary of 20 examined driver behavior factors affecting road safety is presented in Table 1, which are grouped into three levels based on their properties and attributes. Table 1 also provides the description of each factor, abbreviations and the related references. 


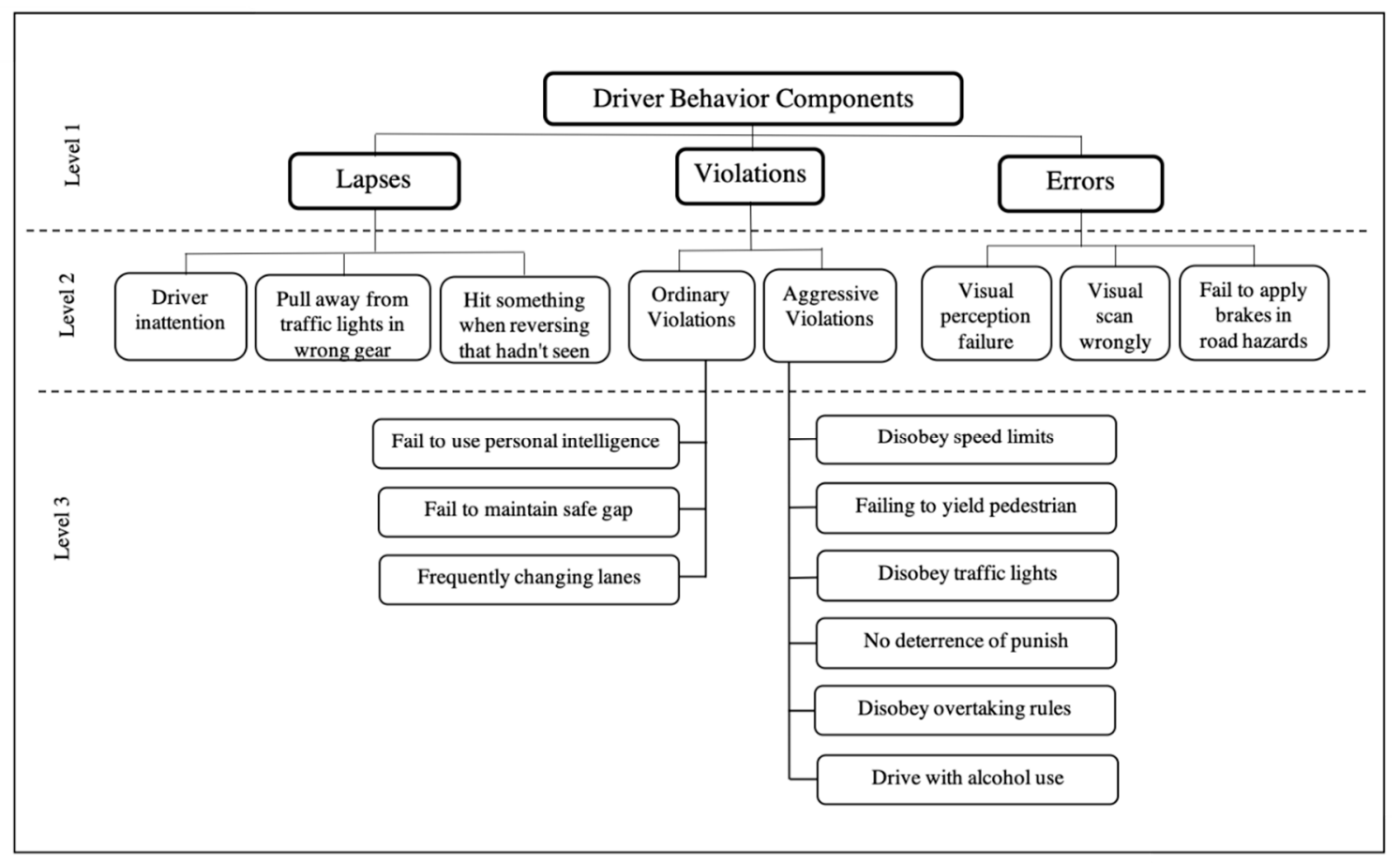

Figure 1. The hierarchical structure of the driver behavior criteria.

Table 1. Presentation of driver behavior factors and abbreviations.

\begin{tabular}{|c|c|c|}
\hline & Driver Behavior Factors & Importance for Road Safety \\
\hline \multirow{3}{*}{ Level 1} & Violations (C1) & $\begin{array}{l}\text { Road Traffic Violations (RTVs) are the most critical that cause certain } \\
\text { risk to other road users [21] }\end{array}$ \\
\hline & Lapses (C2) & $\begin{array}{l}\text { Lapses were noticed as a predictor in accident involvement among } \\
\text { other predictors in a Qatar-based study [22] }\end{array}$ \\
\hline & Errors (C3) & $\begin{array}{l}\text { It has been argued that both driving errors and driving style are } \\
\text { correlates of crash involvement [23] }\end{array}$ \\
\hline \multirow{8}{*}{ Level 2} & Ordinary violations (C11) & $\begin{array}{l}\text { The study results also confirm the importance of ordinary violations } \\
\text { as a correlate of crash involvement [23] }\end{array}$ \\
\hline & Aggressive violations (C12) & $\begin{array}{l}\text { Aggressive violations were significant correlates of crash involvement } \\
\text { but with strong connection with ordinary violations [24] }\end{array}$ \\
\hline & Driver inattention (C21) & $\begin{array}{c}\text { Klauer et al. (2006) determined that approximately } 25-30 \% \text { of traffic } \\
\text { conflicts are related to driver inattention but argued that the true } \\
\text { involvement of inattention may be as high } 70 \%[25]\end{array}$ \\
\hline & $\begin{array}{l}\text { Pull away from traffic lights in } \\
\text { wrong gear (C22) }\end{array}$ & $\begin{array}{l}\text { The UK-based study identified "Pull away from traffic lights in wrong } \\
\text { gear" as aberrant driver behavior [26] }\end{array}$ \\
\hline & $\begin{array}{l}\text { Hit something when reversing } \\
\text { that hadn't seen (C23) }\end{array}$ & $\begin{array}{l}\text { "Hit something when reversing that hadn't seen" was loaded highest } \\
\text { with one other factor in factor analysis [27] }\end{array}$ \\
\hline & Visual perception failure (C31) & $\begin{array}{l}\text { Perception failure (both on the part of the rider and other road users) } \\
\text { was examined as the most common factor in crashes [28] }\end{array}$ \\
\hline & Visual scan wrongly (C32) & Wide visual scanning is an important element of safe driving [29] \\
\hline & $\begin{array}{l}\text { Fail to apply brakes in road } \\
\text { hazards (C33) }\end{array}$ & $\begin{array}{c}\text { "Hazard-based duration model" was developed to investigate the } \\
\text { effects of vehicle dynamic variables on a driver's braking } \\
\text { behavior [30] }\end{array}$ \\
\hline
\end{tabular}


Table 1. Cont.

\begin{tabular}{|c|c|c|}
\hline & Driver Behavior Factors & Importance for Road Safety \\
\hline \multirow{9}{*}{ Level 3} & $\begin{array}{l}\text { Fail to use personal } \\
\text { intelligence (C111) }\end{array}$ & $\begin{array}{l}\text { Intelligent transport system is helping to change the safety focus from } \\
\text { minimizing the consequences of crashes [31] }\end{array}$ \\
\hline & $\begin{array}{l}\text { Fail to maintain safe } \\
\text { gap (C112) }\end{array}$ & $\begin{array}{l}\text { Gap-acceptance was found as one of the most important factors of } \\
\text { traffic safety at intersections [32] }\end{array}$ \\
\hline & $\begin{array}{l}\text { Frequently changing } \\
\text { lanes (C113) }\end{array}$ & $\begin{array}{c}\text { Risk exposure level specifies how long a subject vehicle is exposed to } \\
\text { a hazardous situation that could possibly lead to a crash while } \\
\text { making a lane change [33] }\end{array}$ \\
\hline & Disobey speed limits (C121) & $\begin{array}{l}\text { Speeding is one of the serious and most common aberrant driving } \\
\text { behaviors that negatively affect the safety of the violators themselves } \\
\text { and the whole motorized community [34] }\end{array}$ \\
\hline & Fail to yield pedestrian (C122) & $\begin{array}{l}\text { In terms of contributing factors, } 14.2 \% \text { of fatalities were attributed to } \\
\text { failure to yield right of way at the crossing [5] }\end{array}$ \\
\hline & Disobey traffic lights (C123) & $\begin{array}{l}\text { One of the possible causes for the high number of crashes and injuries } \\
\text { is due to beating traffic lights [35] }\end{array}$ \\
\hline & No deterrence of punish (C124) & $\begin{array}{l}\text { A } 2016 \text { meta-analysis indicated that fine increases between } 50 \text { and } \\
100 \% \text { are associated with a } 15 \% \text { reduction in traffic violations [36] }\end{array}$ \\
\hline & $\begin{array}{l}\text { Disobey overtaking } \\
\quad \text { rules }(\mathrm{C} 125)\end{array}$ & $\begin{array}{l}\text { It was analyzed that dangerous overtaking accounted for } 41 \% \text { of all } \\
\text { drivers who died in traffic in } 2006 \text { [37] }\end{array}$ \\
\hline & Drive with alcohol use (C126) & $\begin{array}{l}\text { Even with a small amount of alcohol consumption, drivers are twice } \\
\text { likely to be involved in traffic accidents than sober drivers [38] }\end{array}$ \\
\hline
\end{tabular}

\section{Materials and Methods}

As discussed in the introduction, it is important for AHP to solve road safety issues for sustainable traffic safety; thus, we applied the Analytic Hierarchy Process (AHP) for the assessment of nominated driver behavior criteria affecting road safety. The primary step of the methodology was to construct a hierarchy structure for the driver behavior criteria and sub-criteria. A driver behavior questionnaire survey was used as a tool to collect driver behavior data from three driver evaluator groups. Furthermore, the procedure involved to construct the pairwise comparison matrix (PCM) of criteria and scale the matrix based on relative scale measurement. After the measurement of the eigenvector of the criterion, the consistency ratio was computed. The next step was to calculate the composite priority (overall weights in the entire hierarchy). The last step was to rank the alternatives for each level and detect the agreement level among the evaluator groups. Finally, the overall rank for each criterion for all evaluator groups was highlighted by implementing the geometric mean technique.

\subsection{Sample Characteristics}

The AHP questionnaire survey was designed to enumerate the driver behavior factors associated with road safety. The questionnaire was used as a tool in a personal interview with three car driver groups in Budapest city, Hungary. The first driver group (Group A) contained foreign divers having a Hungarian driver license with considerable driving experience. It was noted that significant regional differences exist, reflecting perhaps the individualities related to the mentality and history of each region; these differences should play an important role in planning safety campaigns and policies [39]. Foreign drivers in Hungary were observed to have a specific behavior such as failing to yield to the person on your right, which is a cause of accidents. A driver's license can be issued to foreign citizens in Hungary who have stayed for 6 months in Hungary before the issuance of the driver's license. The second group (Group B) involved experienced drivers with high driving experience. It was observed in a study that increasing driving experience and exposure to traffic increases the level of driving skills with less traffic violations and accidents [40]. The third group (Group C) included young drivers with less driving experience. Young people are overrepresented in traffic crashes, with most of the drivers being young men [41-43]. The study was illustrated for 35 randomly selected participants 
for each group. These participants were sought to provide linguistic judgement data based on the AHP questionnaire.

The questionnaire survey was based on two parts: The first part aimed to collect demographic data about the participants and results were tabulated in Table 2. The results showed the mean and standard deviation (SD) values of each observed characteristics. We used digits $(1,0)$ for statistical evaluation purpose to describe some characteristics such as gender and driver occupation. Moreover, the important noticeable results are that group A contained foreign drivers which have a mean value of 1 for gender which means that they are all males. Also, group B contained experienced drivers which have a mean value of 1 for driver occupation which means that they all have jobs. The importance of selected groups for analysis has been discussed in the above paragraph. The second part aimed to explore and study the driver behavior criteria for road safety as discussed in the results and discussion section.

Table 2. Demographic characteristics of participants.

\begin{tabular}{cccc}
\hline Variables & Group A & Group B & Group C \\
\hline $\mathbf{N}$ & $\mathbf{3 5}$ & $\mathbf{3 5}$ & $\mathbf{3 5}$ \\
\hline Age & & & \\
Mean & 32.246 & 38.274 & 21.635 \\
SD & 5.641 & 3.672 & 2.737 \\
\hline Gender (1 = male, 0 = female) & & & \\
Mean & 1.0 & 0.883 & 0.785 \\
SD & 0.0 & 0.353 & 0.317 \\
\hline Driving Experience & & & \\
Mean & 3.523 & 17.326 & 1.852 \\
SD & 2.721 & 2.714 & 1.041 \\
\hline Driver Occupation & & & \\
(1 = job, 0 student) & & & 0.361 \\
Mean & 0.912 & 1.0 & 0.648 \\
SD & 0.542 & 0.0 &
\end{tabular}

\subsection{Pairwise Comparison (PC)}

The experts estimated the relative measurement between the criteria and the alternatives using pairwise comparison (PC) proposed by Saaty in 1977 [44]. The questionnaire survey was arranged according to the PCM-s, and binary comparisons were performed from decision options for examined criteria. In creating a binary comparison matrix, each element weight was compared with another element in the structure using Saaty's eigenvector method. The principal eigenvector of the matrix exhibited the maximum eigenvalue of six which is the biggest matrix in the hierarchical structure as presented in Table 3. It is obvious that this can be extended to any size-consistent PCM. Thus, the principal eigenvector of consistent PCM-s can be easily calculated [45] and characterizes the matrix elements perfectly. However, in AHP, the evaluators most likely do not evaluate PCM-s consistently by the provided Saaty-scale (Table 4), a judgment from the scale is a ratio indicating how many times the dominant factor is more important than the dominated one.

Table 3. The structure of $(6 \times 6)$ consistent theoretical PC matrices.

\begin{tabular}{llllll}
\hline $\boldsymbol{w}_{1} / \boldsymbol{w}_{1}$ & $\boldsymbol{w}_{1} / \boldsymbol{w}_{2}$ & $\boldsymbol{w}_{1} / \boldsymbol{w}_{3}$ & $\boldsymbol{w}_{1} / \boldsymbol{w}_{4}$ & $\boldsymbol{w}_{1} / \boldsymbol{w}_{5}$ & $\boldsymbol{w}_{1} / \boldsymbol{w}_{6}$ \\
\hline$w_{2} / w_{1}$ & $w_{2} / w_{2}$ & $w_{2} / w_{3}$ & $w_{2} / w_{4}$ & $w_{2} / w_{5}$ & $w_{2} / w_{6}$ \\
$w_{3} / w_{1}$ & $w_{3} / w_{2}$ & $w_{3} / w_{3}$ & $w_{3} / w_{4}$ & $w_{3} / w_{5}$ & $w_{3} / w_{6}$ \\
$w_{4} / w_{1}$ & $w_{4} / w_{2}$ & $w_{4} / w_{3}$ & $w_{4} / w_{4}$ & $w_{4} / w_{5}$ & $w_{4} / w_{6}$ \\
$w_{5} / w_{1}$ & $w_{5} / w_{2}$ & $w_{5} / w_{3}$ & $w_{5} / w_{4}$ & $w_{5} / w_{5}$ & $w_{5} / w_{6}$ \\
$w_{6} / w_{1}$ & $w_{6} / w_{2}$ & $w_{6} / w_{3}$ & $w_{6} / w_{4}$ & $w_{6} / w_{5}$ & $w_{6} / w_{6}$ \\
\hline
\end{tabular}


Table 4. Saaty's judgment scale of relative weight score of criteria [44].

\begin{tabular}{cc}
\hline Numerical Values & Explanation \\
\hline 1 & Two factors contribute equally \\
3 & Experience and judgment favor one factor over another \\
5 & A factor is strongly favored \\
7 & A factor is very strongly dominant \\
9 & A factor is favored by at least an order of magnitude \\
$2,4,6,8$ & Used to compromise between two judgments \\
\hline
\end{tabular}

For experiential PCM-s: reciprocity is indeed fulfilled for every PCM,

$$
x_{j i}=1 / x i j
$$

where $x_{i i}=1$ provided. However, the consistency is most likely not fulfilled for empirical matrices. The consistency criterion:

$$
x_{i k}=x_{i j} \cdot x_{j k}
$$

Participants were asked to indicate how often they committed each of the examined driver behavior factors based on a Saaty scale as shown in Table 4 .

\subsection{The AHP Approach}

The analytic hierarchy process (AHP) is a mathematical device in multi-criteria decision making which designs the decision factors in a hierarchic problem structure [46]. AHP was widely used to make efficient and effective decisions for decision-making problems for multiple fields like civil engineering, transport engineering and industrial engineering [47-50]. The AHP method helps the analyst not only to identify the key factors, but also to determine the allocation of resources and consider different tangible and non-tangible preferences. By using AHP, decisions can be made using weights based on subjective pairwise relative comparisons through multilevel hierarchical structures. AHP is a systematic and comprehensive method to solve multi-criteria decision problems and avoid inconsistencies in the decision-making process. The use of the application is illustrated below.

Despite the empirical matrices filled by the evaluators are generally not consistent, in the eigenvector method the calculation of the eigenvector coordinates is the same as for consistent matrices. Because of this, Saaty invented the consistency check in AHP that ensures that all matrices meet the consistency criterion of acceptable inconsistency.

$$
\mathrm{CI}=\frac{\lambda_{\max }-\mathrm{m}}{\mathrm{m}-1}
$$

where $\mathrm{CI}$ is the Consistency Index and $\lambda_{\max }$ is the maximum eigenvalue of the PCM, while, $\mathrm{m}$ represents the number of rows in the matrix. However, $\mathrm{CR}$ can be determined by the following equation:

$$
\mathrm{CR}=\mathrm{CI} / \mathrm{RI}
$$

where RI is the average CI value of randomly generated PCM of the same size (Table 5).

Table 5. RI indices from randomly generated matrices.

\begin{tabular}{ccccccccccc}
\hline $\boldsymbol{m}$ & $\mathbf{1}$ & $\mathbf{2}$ & $\mathbf{3}$ & $\mathbf{4}$ & $\mathbf{5}$ & $\mathbf{6}$ & $\mathbf{7}$ & $\mathbf{8}$ & $\mathbf{9}$ & $\mathbf{1 0}$ \\
\hline RI & 0 & 0 & 0.58 & 0.9 & 1.12 & 1.24 & 1.32 & 1.41 & 1.45 & 1.49 \\
\hline
\end{tabular}

In the AHP method, the acceptable value of Consistency Ratio (CR) is CR $<0.1$.

In the first level of the structured hierarchical model, the elements of $c_{12}, c_{13}, c_{23}$ were filled by the different evaluator groups in order to compare among C1, C2 and C3. 
The evaluators filled total matrices in such a way: four $(3 \times 3)$ matrices (one $(3 \times 3)$ matrix in level $1+2(3 \times 3)$ matrices in level $2+$ one $(3 \times 3)$ matrix in level 3$)$ as shown in Table 6, one $(2 \times 2)$ matrix in level 2 as shown in Table 7 , and one $(6 \times 6)$ matrix in level 3 as shown in Table 8 .

Table 6. The constructed PC matrix for Level 1.

\begin{tabular}{llll}
\hline $\boldsymbol{L} 1$ & $C 1$ & $C 2$ & $C 3$ \\
\hline $\boldsymbol{C 1}$ & $c_{11}$ & $c_{12}$ & $c_{13}$ \\
$C 2$ & $c_{21}$ & $c_{22}$ & $c_{23}$ \\
$C 3$ & $c_{31}$ & $c_{32}$ & $c_{33}$ \\
\hline
\end{tabular}

Table 7. The constructed PC matrix for Level 2.

\begin{tabular}{ccc}
\hline L2C1 & $C 11$ & $C 12$ \\
\hline$C 11$ & $c_{111}$ & $c_{121}$ \\
$C 12$ & $c_{211}$ & $c_{222}$ \\
\hline
\end{tabular}

Table 8. The constructed PC matrix for Level 3.

\begin{tabular}{ccccccc}
\hline L1C12 & $C 121$ & $C 122$ & $C 123$ & $C 124$ & $C 125$ & $C 126$ \\
\hline$C 121$ & $c_{1112}$ & $c_{1212}$ & $c_{1312}$ & $c_{1412}$ & & $c_{1612}$ \\
$C 122$ & $c_{2112}$ & $c_{2212}$ & $c_{2312}$ & & & \\
$C 123$ & $c_{3112}$ & $c_{3212}$ & $c_{3312}$ & & & \\
$C 124$ & $c_{4112}$ & & & & & \\
$C 125$ & & & & & & $c_{6612}$ \\
$C 126$ & & & & & & \\
\hline
\end{tabular}

The constructed PC of the $\mathrm{m} \times \mathrm{m}$ matrix $A$ corresponding to the eigenvalue $\lambda_{\max }$ of $A$ is the set of all eigenvectors of $A$ corresponding to $\lambda_{\max }$.

If $A$ is a consistent square matrix, then the equivalent equation in standard form will be

$$
\mathrm{Aw}=\lambda_{\max } \mathrm{w}
$$

The eigenvectors make up the null space of $\left(A-\lambda_{\max } . I\right)$. When we know the maximum eigenvalue $\lambda_{\max }$ of the consistent matrix $A$, the eigenvector could be found

$$
A w-\lambda_{\max } w=0 \Longleftrightarrow A w-\lambda_{\max } \cdot I . w=0 \Longleftrightarrow\left(A-\lambda_{\max } \cdot I\right) w=0
$$

For aggregating the evaluators' answers, the most popular aggregation procedure for the geometric mean was employed [51]. If " $h$ " evaluators take part in the procedure, an aggregated matrix is to be created as:

$$
A=\left[\sqrt[h]{\prod_{k=1}^{n} x_{i j k}}\right] i, j=1, \ldots, m
$$

where $x_{i j k}$ denotes entries, in the same position $(i, j)$, of PCM-s, filled in by the $k$-th evaluators.

Afterwards, the right-side eigenvector is to be computed by Equation (7) for the aggregated matrices, and final weight scores are gained by multiplying the eigenvector coordinates with the respective coordinates from the previous level of the hierarchy.

Sensitivity analysis enables in understanding the effects of changes in the main criteria on the sub-criteria ranking and helps the decision maker to check the stability of results throughout the process. 


\subsection{Kendall's Agreement Test}

The need of ranking the factors is very familiar in management, engineering, education, medicine, finance, and politics, in which cases new products, new positions, new elections public or private services are ranked by the public, experts and decision makers [52-54]. However, the natural question is how much the given rankings are in concordance with different groups. To answer this question, the well-known measure, Kendall's coefficient of concordance (W), was proposed by Kendall and Smith in 1939 [55]. W is a normalization of the statistic of the Friedman test, which is considered as a non-parametric statistic technique and can be used for a set of criteria to highlight the agreement level among different raters [56]. For the current study, the authors used Kendall's W technique to highlight the agreement degree (the concordant degree) between the different driver groups for each level in the hierarchal structure. Kendall's concordance degree (W) ranges from 0 (no agreement) to 1 (complete agreement), however, the values' interpretations between 0 and 1 are presented in Table 9.

Table 9. Kendall's W agreement degree scale [55].

\begin{tabular}{cc}
\hline Correlation Coefficient & Interpretation \\
\hline 1 & Perfect agreement \\
$0.9-1$ & very high agreement \\
$0.7-0.9$ & High agreement \\
$0.4-0.7$ & Medium agreement \\
$0.2-0.4$ & Low agreement \\
$0-0.2$ & very low agreement \\
0 & No agreement \\
\hline
\end{tabular}

The calculation process starts by aggregating the ranking of the factor $\mathrm{i}$ throw the following equation:

$$
R_{i}=\sum_{j=1}^{n} r_{i j}
$$

where $R_{i}$ is the aggregated ranking of the factor $i, r_{i j}$ is the rank given to factor $i$ by the evaluator group $j$, and $n$ is the number of rater groups rating $m$ factors.

Then, calculating $R$, which is the mean of the $R_{i}$ values.

$$
\begin{gathered}
R=\frac{n(m+1)}{2} \\
K=\sum_{i=1}^{n}\left(R_{i}-R\right)^{2}
\end{gathered}
$$

where $K$ is the sum-of-squares statistic deviations over the row sums of ranking $R_{i}$.

Following that, Kendall's " $W$ " statistic is between ( 0 and 1$)$, and it can be obtained from the following equation:

$$
\mathrm{W}=\frac{12 K}{n^{2}\left(m^{3}-m\right)}
$$

After implementing the equation, the outcome will estimate the concordance degree among the different rater groups.

\section{Results}

The AHP method determined the degree of importance of driver behavior criteria for road safety based on the responses of the evaluator groups for each level. The entire selected criteria and sub-criteria were compared with each other by PCs. The significance of driver behavior criteria related to road safety was computed by using AHP procedures in the first model of study. For the first level, 
the AHP results revealed the same ranking for driver behavior criteria evaluated by group $\mathrm{B}$ and group $\mathrm{C}$. The results showed that group B and group $C$ evaluated the lapses (C2) as the first ranked criteria followed by errors (C3) based on weight scores as shown in Table 10. The previous study results also observed lapses as the significant driver behavior factor reported by Qatari drivers [26], while group A evaluated errors (C3) as the most important criteria followed by violations (C1) as shown in Table 10.

Table 10. Different priority ranking of criteria by evaluator groups for Level 1.

\begin{tabular}{ccccccc}
\hline \multirow{2}{*}{ Criteria } & \multicolumn{2}{c}{ Group A } & \multicolumn{2}{c}{ Group B } & \multicolumn{2}{c}{ Group C } \\
\cline { 2 - 7 } & Weight & Rank & Weight & Rank & Weight & Rank \\
\hline C1 & 0.40623107 & 2 & 0.30227452 & 3 & 0.22202205 & 3 \\
C2 & 0.15734001 & 3 & 0.36045447 & 1 & 0.53941868 & 1 \\
C3 & 0.43642892 & 1 & 0.33727101 & 2 & 0.23855927 & 2 \\
\hline
\end{tabular}

The AHP approach also measured priority ranking criteria by the evaluator groups for level 2 as shown in Table 11. The results highlighted the fail to apply brakes in road hazards (C33) as the most critical factor by group A. The results showed that aggressive violation (C12) was the most important criteria by evaluator group B, and ordinary violation (C11) was the last-ranked criteria. The results also evaluated that driver inattention (C21) was the first ranked criteria by evaluator group $\mathrm{C}$, while the ordinary violation (C11) was the last ranked criteria in this level.

Table 11. Different priority ranking of criteria by evaluator groups for Level 2.

\begin{tabular}{ccccccc}
\hline \multirow{2}{*}{ Criteria } & \multicolumn{2}{c}{ Group A } & \multicolumn{2}{c}{ Group B } & \multicolumn{2}{c}{ Group C } \\
\cline { 2 - 7 } & Weight & Rank & Weight & Rank & Weight & Rank \\
\hline C11 & 0.05006347 & 6 & 0.0351092 & 7 & 0.03308349 & 7 \\
C12 & 0.35616761 & 7 & 0.26716532 & 1 & 0.18893855 & 2 \\
C21 & 0.07464625 & 3 & 0.12979369 & 4 & 0.2825073 & 1 \\
C22 & 0.01499357 & 8 & 0.05375391 & 6 & 0.09230574 & 5 \\
C23 & 0.06770019 & 4 & 0.17690687 & 3 & 0.16460564 & 3 \\
C31 & 0.06522735 & 5 & 0.07129553 & 5 & 0.03189628 & 8 \\
C32 & 0.10307598 & 2 & 0.03147171 & 8 & 0.07690273 & 6 \\
C33 & 0.26812558 & 1 & 0.23450377 & 2 & 0.12976026 & 4 \\
\hline
\end{tabular}

At the third level, the situation was similar among groups, in which the drive with alcohol use (C126) was enumerated the most significant factor by all three groups. According to Hungarian driving laws, there is zero tolerance policy towards drinking and driving [1]. Also, disobey overtaking rules (C125) was ranked as fourth important criteria for all groups as shown in Table 12.

Table 12. Different priority ranking of criteria by evaluator groups for Level 3.

\begin{tabular}{ccccccc}
\hline \multirow{2}{*}{ Criteria } & \multicolumn{2}{c}{ Group A } & \multicolumn{2}{c}{ Group B } & \multicolumn{2}{c}{ Group C } \\
\cline { 2 - 7 } & Weight & Rank & Weight & Rank & Weight & Rank \\
\hline C111 & 0.01958076 & 8 & 0.00705814 & 9 & 0.01265383 & 7 \\
C112 & 0.02280969 & 6 & 0.01828043 & 6 & 0.00721985 & 9 \\
C113 & 0.00767301 & 9 & 0.00977063 & 8 & 0.01320981 & 5 \\
C121 & 0.02453512 & 5 & 0.00990461 & 7 & 0.01076274 & 8 \\
C122 & 0.05536908 & 2 & 0.04603399 & 3 & 0.01281167 & 6 \\
C123 & 0.05493391 & 3 & 0.05674643 & 2 & 0.03921386 & 2 \\
C124 & 0.02148176 & 7 & 0.0185817 & 5 & 0.01546232 & 3 \\
C125 & 0.04243679 & 4 & 0.02863817 & 4 & 0.01322963 & 4 \\
C126 & 0.15741095 & 1 & 0.10726042 & 1 & 0.09745834 & 1 \\
\hline
\end{tabular}


Kendall's coefficient of concordance $(\mathrm{W})$ value was measured for assessing agreement degree among raters for each level in the second model of study. The concordance value $(\mathrm{W}=0.3333)$ for level 1 showed that there was low agreement between criteria as shown in Table 13. The main driver behavior criteria elements differ from each other due to their original categorization characteristics. However, if we eliminate group A, we can see that the other two groups have a perfect agreement.

Table 13. Kendall's coefficient of concordance (W) result-based priority ranking of criteria for Level 1.

\begin{tabular}{cccccc}
\hline Criteria & Rank of Group A & Rank of Group B & Rank of Group C & $\boldsymbol{R}_{\boldsymbol{i}}$ & $\left(\boldsymbol{R}_{\boldsymbol{i}}-\boldsymbol{R}^{2}\right.$ \\
\hline C1 & 2 & 3 & 3 & 8 & 4 \\
C2 & 3 & 1 & 1 & 5 & 1 \\
C3 & 1 & 2 & 2 & 5 & 1 \\
\hline $\mathrm{m}=3$ & $\mathrm{n}=3$ & $\mathrm{~K}=6$ & $R=6$ & $\mathrm{~W}=0.3333$ \\
\hline
\end{tabular}

The Kendall's coefficient of concordance (W) value was measured for the second level also. The concordance value $(\mathrm{W}=0.5185)$ showed that there was medium agreement between criteria in this level as shown in Table 14. The subfactors in level 2 have some similar influential characteristics for road safety.

Table 14. Kendall's coefficient of concordance (W) result-based priority ranking of criteria for Level 2.

\begin{tabular}{|c|c|c|c|c|c|}
\hline Criteria & Rank of Group A & Rank of Group B & Rank of Group C & $R_{i}$ & $\left(R_{i}-R\right)^{2}$ \\
\hline C11 & 6 & 7 & 7 & 20 & 42.25 \\
\hline C12 & 7 & 1 & 2 & 10 & 12.25 \\
\hline $\mathrm{C} 21$ & 3 & 4 & 1 & 8 & 30.25 \\
\hline $\mathrm{C} 22$ & 8 & 6 & 5 & 19 & 30.25 \\
\hline $\mathrm{C} 23$ & 4 & 3 & 3 & 10 & 12.25 \\
\hline C31 & 5 & 5 & 8 & 18 & 20.25 \\
\hline C32 & 2 & 8 & 6 & 16 & 6.25 \\
\hline C33 & 1 & 2 & 4 & 7 & 42.25 \\
\hline $\mathrm{m}=8$ & $\mathrm{n}=3$ & $K=196$ & $R=13.5$ & \multicolumn{2}{|c|}{$W=0.5185$} \\
\hline
\end{tabular}

The Kendall's coefficient of concordance $(\mathrm{W})$ value was also measured for the third level as well. The concordance value $(\mathrm{W}=0.7852)$ showed that there was high agreement between the criteria ranking for level 3 as shown in Table 15. The subfactors in level 3 are originally types of main category "violations", so these factors have a high connection.

Table 15. Kendall's coefficient of concordance (W) result-based priority ranking of criteria for Level 3.

\begin{tabular}{cccccc}
\hline Criteria & Rank of Group A & Rank of Group B & Rank of Group C & $\boldsymbol{R}_{\boldsymbol{i}}$ & $\left.\boldsymbol{( R}_{\boldsymbol{i}}-\boldsymbol{R}\right)^{2}$ \\
\hline $\mathrm{C} 111$ & 8 & 9 & 7 & 24 & 81 \\
$\mathrm{C} 112$ & 6 & 6 & 9 & 21 & 36 \\
$\mathrm{C} 113$ & 9 & 8 & 5 & 22 & 49 \\
$\mathrm{C} 121$ & 5 & 7 & 8 & 20 & 25 \\
$\mathrm{C} 122$ & 2 & 3 & 6 & 11 & 16 \\
$\mathrm{C} 123$ & 3 & 5 & 2 & 7 & 64 \\
$\mathrm{C} 124$ & 7 & 4 & 3 & 15 & 0 \\
$\mathrm{C} 125$ & 4 & 1 & 4 & 12 & 9 \\
$\mathrm{C} 126$ & 1 & $\mathrm{~K}=424$ & $R=15$ & \multicolumn{2}{c}{$\mathrm{W}=0.7852$} \\
\hline $\mathrm{m}=9$ & $\mathrm{n}=3$ &
\end{tabular}

Predominantly, the preferences among the different groups are quite significant. In the research, a well-known technique was proposed to get a consensual overview for the most important factors 
considering all participants' points of view as shown in Table 16. The final overall ranking of driver behavior criteria was measured based on the examined driver group responses using AHP procedures. The geometric mean technique was implemented to get the consensual scores for all evaluator groups.

Table 16. Overall (consensual) scores.

\begin{tabular}{|c|c|c|c|c|c|}
\hline \multicolumn{2}{|c|}{ Level 1} & \multicolumn{2}{|c|}{ Level 2} & \multicolumn{2}{|c|}{ Level 3} \\
\hline \multicolumn{2}{|c|}{ Driver Behavior Criteria } & \multicolumn{2}{|c|}{ C1 } & \multicolumn{2}{|c|}{ C11 } \\
\hline $\mathrm{C} 1$ & 0.31987043 & C11 & 0.12946629 & C111 & 0.37962049 \\
\hline $\mathrm{C} 2$ & 0.33200763 & $\mathrm{C} 12$ & 0.87053371 & C112 & 0.36848157 \\
\hline \multirow[t]{8}{*}{ C3 } & 0.34812194 & & & C113 & 0.25189794 \\
\hline & & $\mathrm{C} 21$ & 0.29480108 & \multicolumn{2}{|c|}{ C12 } \\
\hline & & $\mathrm{C} 22$ & 0.27123868 & C121 & 0.05407275 \\
\hline & & $\mathrm{C} 23$ & 0.41039785 & C122 & 0.12394574 \\
\hline & & \multicolumn{2}{|c|}{ C3 } & C123 & 0.19138464 \\
\hline & & C31 & 0.16303663 & $\mathrm{C} 124$ & 0.06989651 \\
\hline & & $\mathrm{C} 32$ & 0.19597869 & C125 & 0.09857295 \\
\hline & & C33 & 0.64098467 & $\mathrm{C} 126$ & 0.46212741 \\
\hline
\end{tabular}

The results of the overall rank for the first level illustrated that errors (C3) was the most significant criteria with the highest score (0.34812194) followed by the lapses (C2) with a score of $(0.33200763)$. Parker et al. [10] also stated that errors and lapses were more of a concern among the elderly. The results found violations (C1) as the last ranked criteria by the evaluator groups as shown in Table 17.

Table 17. Overall priority ranking of criteria for level 1 considering all evaluator groups.

\begin{tabular}{ccc}
\hline Criteria & Weight & Rank \\
\hline C1 & 0.31987043 & 3 \\
C2 & 0.33200763 & 2 \\
C3 & 0.34812194 & 1 \\
\hline
\end{tabular}

The overall ranks of subfactors for the second level showed that the aggressive violation (C12) was the most significant subfactor with the highest score $(0.27845799)$ followed by the fail to apply brakes in road hazards (C33) with a score of (0.22314083). The results also showed the last-ranked subfactor ordinary violations (C11) with the lowest score (0.0414) as shown in Table 18.

Table 18. Overall priority ranking of criteria for level 2 considering all evaluator groups.

\begin{tabular}{ccc}
\hline Criteria & Weight & Rank \\
\hline C11 & 0.04141244 & 8 \\
C12 & 0.27845799 & 1 \\
C21 & 0.09787621 & 4 \\
C22 & 0.09005331 & 5 \\
C23 & 0.13625522 & 3 \\
C31 & 0.05675663 & 7 \\
C32 & 0.06822448 & 6 \\
C33 & 0.22314083 & 2 \\
\hline
\end{tabular}

The overall ranks of subfactors for level 3 showed that drive with alcohol use (C126) was the most significant subfactor with the highest score (0.12868307) followed by disobey traffic lights (C123) and the fail to yield pedestrian (C122). The results also revealed that frequently changing lanes (C113) was the last ranked subfactor with the lowest score (0.01043171) as shown in Table 19. 
Table 19. Overall priority ranking of criteria for level 3 considering all evaluator groups.

\begin{tabular}{ccc}
\hline Criteria & Weight & Rank \\
\hline C111 & 0.01572101 & 7 \\
C112 & 0.01525972 & 8 \\
C113 & 0.01043171 & 9 \\
C121 & 0.01505699 & 6 \\
C122 & 0.03451368 & 3 \\
C123 & 0.05329258 & 2 \\
C124 & 0.01946324 & 5 \\
C125 & 0.02744843 & 4 \\
C126 & 0.12868307 & 1 \\
\hline
\end{tabular}

\section{Advantages and Limitations of Using AHP in Road Safety}

Although AHP technique is more than three decades old, the facts of flexibility and robustness result in its extensive application in many fields. AHP is an efficient and comprehensive method to solve multi-criteria decision issues and avoid inconsistencies in the decision-making process [57]. The AHP application enables the decision-makers to better understand the complex relationships of the significant driver behavior factors related to road safety in the decision-making which helps in subsequently improving the reliability of decisions for sustainable traffic safety. However, the AHP method creates and deals with a very unbalanced scale of judgment and it does not consider the uncertainty associated with the mapping of human judgment to a number by natural language [58]. Moreover, the fuzzy AHP has been considered a more advanced technique to get more robust results, where the fuzzy AHP reflects more reality because of using the fuzzy numbers in evaluating the questionnaire survey.

\section{Conclusions}

The significance of driver behavior elements determining road safety is crucial and difficult to assess. The main contribution of this study is the combined use of popular multicriteria methods for ranking and prioritizing the critical driver behavior criteria and not applying statistical data analysis. It must be stressed that the introduced model does not substitute the statistical calculations, but it is well applicable for amending them by human knowledge acquisition. As presented, the AHP has been used to reflect choices based on the evaluator groups, while Kendall's degree of correlation has been applied to estimate the correlation among the examined groups based on perceived road safety issues. This combined process can serve as a supporting tool for assisting the decision makers to prioritize the important driver behavior criteria for the application of efficient and sustainable traffic safety system.

The main novelty of this paper is to identify and quantify the significant driver behavior criteria in Budapest city using the pairwise comparison method of AHP. The AHP study results found the "Lapses" as the most significant driver behavior criteria based on the evaluation of young drivers and experienced drivers' responses on perceived road safety issues, while the foreign drivers evaluated the "Errors" as the most significant criteria affecting road safety. The overall results for the first level also showed the higher ranks for "Errors" and "Lapses" as compared to "Violations". The final AHP results for sub-criteria have crucial considerations in the study. The overall results in the second level determined that "Aggressive violation" was the most critical sub-criteria and "Ordinary violation" was the last-ranked sub-criteria. Also, for the third level, the "Drive with alcohol use" was the most significant sub-criteria and "Frequently changing lanes" was the last-ranked sub-criteria. Kendall correlation method determined the correlation between rater groups for examined driver behavior criteria for each level. This correlation was higher among evaluator groups at the third level as compared to other levels.

In summary, the objective of this study is to help the motor community by shining the light on the most significant driver behavior factors which may lead to road safety issues. The findings suggest that 
there is a need to focus on specific driver behavior factors in the planning of road safety campaigns or education courses to improve the risk perception and critical driving behaviors among different driver groups. Linkage of the research data with traffic management agencies and transport authorities could help to adopt effective road safety strategies and improve the sustainable level of traffic safety. This research evaluation could also be further used to compare the estimated significant driver behavior factors based on dynamic analysis and road crashes involved in driver behavior factors based on statistical analysis.

Author Contributions: Conceptualization, D.F. and S.M.; methodology, S.M. and S.D.; validation, S.M.; data curation, D.F.; writing — original draft preparation, D.F. and S.M.; writing—review and editing, D.F. and S.D.

Funding: This research received no external funding.

Conflicts of Interest: The authors declare no conflict of interest.

\section{References}

1. World Health Organization (WHO). Legal BAC Limits by Country; WTO: Geneva, Switzerland, 2015.

2. Valette, L. Road Safety: New Statistics Call for Fresh Efforts to Save Lives on EU Roads; European Commission Press Release: Brussels, Belgium, 2016.

3. OECD/ITF. Road Safety Annual Report; OECD: Paris, France; ITF: London, UK, 2016.

4. KSH. Road Accidents Involving Personal Injury (2001-2017); KSH: Budapest, Hungary, 2018.

5. NHTSA (National Highway Traffic Safety Administration). National Motor Vehicle Crash Causation Survey; U.S Department of Transportation: Washington, DC, USA, 2008.

6. Reason, J. Human Error; Cambridge University Press: Cambridge, UK, 1990.

7. Parker, D.; Manstead, A.S.R.; Stradling, S.G. Extending the theory of planned behaviour: The role of personal norm. Br. J. Soc. Psychol. 1995, 34, 127-137. [CrossRef]

8. Lajunen, T.; Parker, D.; Summala, H. The Manchester driver behaviour questionnaire: A cross-cultural study. Accid. Anal. Prev. 2004, 36, 231-238. [CrossRef]

9. Lawton, R.; Parker, D.; Manstead, A.S.; Stradling, S.G. The role of affect in predicting social behaviors: The case of road traffic violations. J. Appl. Soc. Psychol. 1997, 27, 1258-1276. [CrossRef]

10. Parker, D.; McDonald, L.; Rabbitt, P.; Sutcliffe, P. Elderly drivers and their accidents: The Aging Driver Questionnaire. Accid. Anal. Prev. 2000, 32, 751-759. [CrossRef]

11. Rimmö, P.A. Aberrant driving behaviour: Homogeneity of a four-factor structure in samples differing in age and gender. Ergonomics 2002, 45, 569-582. [CrossRef]

12. Pai, C.-W. Motorcyclist injury severity in angle crashes at T-junctions: Identifying significant factors and analysing what made motorists fail to yield to motorcycles. Saf. Sci. 2009, 47, 1097-1106. [CrossRef]

13. Yu, S.; Jia, Y.; Sun, D. Identifying Factors that Influence the Patterns of Road Crashes Using Association Rules: A case Study from Wisconsin, United States. Sustainability 2019, 11, 1925. [CrossRef]

14. Stanojevic, P.; Lajunen, T.; Jovanovic, D.; Sârbescu, P.; Kostadinov, S. The driver behaviour questionnaire in South-East Europe countries: Bulgaria, Romania and Serbia. Transp. Res. Part F 2018, 53, 24-33. [CrossRef]

15. Cordazzo, S.T.D.; Scialfa, C.T.; Ross, R.J. Modernization of the Driver Behaviour Questionnaire. Accid. Anal. Prev. 2016, 87, 83-91. [CrossRef]

16. Farooq, D.; Juhasz, J. Analysis of Young Driver Behaviour related to Road Safety Issues in Pakistan and Hungary. In Proceedings of the 3rd World Congress on Civil, Structural, and Environmental Engineering (CSEE'18), Budapest, Hungary, 8-10 April 2018; p. 109.

17. De Oña, J.; De Oña, R.; Eboli, L.; Forciniti, C.; Mazzulla, G. How to identify the key factors that affect driver perception of accident risk. A comparison between Italian and Spanish driver behavior. Accid. Anal. Prev. 2014, 73, 225-235. [CrossRef]

18. Navneet, B.; Rai, K. Strategic Decision Making: Applying the Analytic Hierarchy Process; Springer: London, $\mathrm{UK}, 2004$.

19. Martín, L.; Baena, L.; Garach, L.; López, G.; de Oña, J. Using data mining techniques to road safety improvement in Spanish roads. Procedia-Soc. Behav. Sci. 2014, 160, 607-614. [CrossRef]

20. Mallia, L.; Lazuras, L.; Violani, C.; Lucidi, F. Crash risk and aberrant driving behaviors among bus drivers: The role of personality and attitudes towards traffic safety. Accid. Anal. Prev. 2015, 79, 145-151. [CrossRef] 
21. Stradling, S.G.; Meadows, M.L.; Beatty, S. Driving as part of your work may damage your health. Behav. Res. Road Saf. 2000, IX, 1-9.

22. Bener, A.; Al Maadid, M.G.; Özkan, T.; Al-Bast, D.A.; Diyab, K.N.; Lajunen, T. The impact of four-wheel drive on risky driver behaviours and road traffic accidents. Transp. Res. Part F Traffic Psychol. Behav. 2008, 11, 3242013333. [CrossRef]

23. Winter, J.C.F.; Dodou, D. The Driver Behavior Questionnaire as a predictor of accidents: A meta-analysis. J. Saf. Res. 2010, 41, 463-470. [CrossRef]

24. Rowe, R.; Roman, G.D.; Mckenna, F.P.; Barker, E.; Poulter, D. Measuring errors and violations on the road: A bifactor modeling approach to the Driver Behavior Questionnaire. Accid. Anal. Prev. 2014, 74, 118-125. [CrossRef]

25. Klauer, S.G.; Dingus, T.A.; Neale, V.L.; Sudweeks, J.D.; Ramsey, D.J. The Impact of Driver Inattention on Near Crash/Crash Risk: An Analysis Using the 100-Car Naturalistic Driving Study Data; Report No: DOT-HS-810-594; National Highway Traffic Safety Administration: Washington, DC, USA, 2006.

26. Stradling, S.G.; Parker, D.; Lajunen, T.; Meadows, M.L.; Xiel, C.Q. Normal behavior and traffic safety: Violations, errors, lapses and crashes. In Transportation; Traffic Safety and Health-Human Behavior; Springer: Berlin/Heidelberg, Germany, 2000; pp. 279-295.

27. Bener, A.B.; Verjee, M.; Dafeeah, E.E.; Yousafzai, M.T.; Mari, S.; Hassib, A.; Al-Khatib, H.; Choi, M.K.; Nema, N.; Özkan, T.; et al. A Cross "Ethnical" Comparison of the Driver Behaviour Questionnaire (DBQ) in an Economically Fast Developing Country. Glob. J. Health Sci. 2013, 5, 165-175. [CrossRef]

28. ACEM. In-Depth Investigations of Accidents Involving Powered Two Wheelers; Report Number 2; Avenue de la Joyeuse Entrée 1-1040; ACEM: Brussels, Belgium, 2004.

29. Pradhan, A.K.; Kaigang, L.; Bingham, C.R.; Bruce, G.; Simons-Morton, E.D.; Ouimet, M.C.; Shope, J.T. Peer Passenger Influences on Male Adolescent Drivers' Visual Scanning Behavior During Simulated Driving. J. Adolesc. Health 2014, 54, 42-49. [CrossRef]

30. Bella, F.; Silvestri, M. Effects of safety measures on driver's speed behavior at pedestrian crossings. Accid. Anal. Prev. 2015, 83, 111-124. [CrossRef]

31. Khorasani, G.; Tatari, A.; Yadollahi, A.; Rahimi, M. Evaluation of Intelligent Transport System in Road Safety. Int. J. Chem. Environ. Biol. Sci. (IJCEBS) 2013, 1, 110-118.

32. Niezgoda, M.; Kamiski, T.; Kruszewski, M. Measuring Driver Behaviour-Indicators for Traffic Safety. J. KONES Power. Transp. 2012, 19, 503-511. [CrossRef]

33. Park, H.; Oh, C.; Moon, J. Real-Time Estimation of Lane Change Risks Based on the Analysis of Individual Vehicle Interactions. Transp. Res. Rec. J. Transp. Res. Board 2018, 2672, 39-50. [CrossRef]

34. Hassan, H.M.; Shawky, M.; Kishta, M.; Garib, A.M.; Al-Harthei, H.A. Investigation of drivers' behavior towards speeds using crash data and self-reported questionnaire. Accid. Anal. Prev. 2017, 98, 348-358. [CrossRef]

35. Subramaniam, K.; Phang, W.K.; Hayati, K.S. Traffic light violation among motorists in Malaysia. IATSS Res. 2007, 31, 67-73.

36. Goldenbeld, C. Increasing Traffic Fines. SWOV; Institute for Road Safety Research: The Hague, The Netherlands, 2017.

37. Walker, I. Drivers overtaking bicyclists: Objective data on the effects of riding position, helmet use, vehicle type and apparent gender. Accid. Anal. Prev. 2007, 39, 417-425. [CrossRef]

38. Arnedt, A.; Wilde, W.; Munt, M.; Maclean, M. Simulated driving performance following prolonged wakefulness and alcohol consumption: Separate and combined contributions to impairment. J. Sleep Res. 2000, 9, 233-241. [CrossRef]

39. Karlaftis, M.G.; Golias, I. Effects of road geometry and traffic volumes on rural roadway accident rates. Accid. Anal. Prev. 2002, 34, 357-365. [CrossRef]

40. Chu, W.; Wu, C.; Zhang, H.; Zhang, L. Investigating the Relationship Between Driving Skills, Driving Experience and Aggressive Driving Behaviors in China. In Proceedings of the Transportation Research Board 96th Annual Meeting, Washington, DC, USA, 8-12 January 2017.

41. Truelove, V.; Freeman, J.; Davey, J. You can't be deterred by stuff you don't know about: Identifying factors that influence graduated driver licensing rule compliance. Saf. Sci. 2019, 111, 313-323. [CrossRef]

42. Constantinou, E.; Panayiotou, G.; Konstantinou, N.; Loutsiou-Ladd, A.; Kapardis, A. Risky and aggressive driving in young adults: Personality matters. Accid. Anal. Prev. 2011, 43, 1323-1331. [CrossRef] 
43. Özkan, T.; Lajunen, T. What causes the differences in driving between young men and women? The effects of gender roles and sex on young drivers' driving behaviour and self-assessment of skills. Transp. Res. Part F Traffic Psychol. Behav. 2006, 9, 269-277. [CrossRef]

44. Saaty, T.L. A scaling method for priorities in hierarchical structures. J. Math. Psychol. 1977, 15, $234-281$. [CrossRef]

45. Saaty, T.L. Decision Making with Dependence and Feedback: The Analytic Network Process; RWS: Pittsburgh, PA, USA, 1996.

46. Saaty, T.L. How to make a decision: The analytic hierarchy process. Interfaces 1994, 24, 19-43. [CrossRef]

47. Duleba, S.; Moslem, S. Sustainable Urban Transport Development with Stakeholder Participation, an AHP-Kendall Model: A Case Study for Mersin. Sustainability 2018, 10, 3647. [CrossRef]

48. Kokangül, A.; Polat, U.; Dağsuyu, C. A new approximation for risk assessment using the AHP and Fine Kinney methodologies. Saf. Sci. 2017, 91, 24-32. [CrossRef]

49. Wang, J.; Li, M.; Liu, Y.; Zhang, H.; Zou, W.; Cheng, L. Safety assessment of shipping routes in the South China Sea based on the fuzzy analytic hierarchy process. Saf. Sci. 2014, 62, 46-57. [CrossRef]

50. Wang, Q.; Wang, H.; Qi, Z. An application of nonlinear fuzzy analytic hierarchy process in safety evaluation of coal mine. Saf. Sci. 2016, 86, 78-87. [CrossRef]

51. Krejčí, J.; Stoklasa, J. Aggregation in the analytic hierarchy process: Why weighted geometric mean should be used instead of weighted arithmetic mean. Expert Syst. Appl. 2018, 114, 97-106. [CrossRef]

52. Couso, I.; Strauss, O.; Saulnier, H. Kendall's rank correlation on quantized data: An interval-valued approach. Fuzzy Sets Syst. 2018, 343, 50-64. [CrossRef]

53. Marozzi, M. Construction, dimension reduction and uncertainty analysis of an index of trust in public institutions. Qual. Quant. 2014, 48, 939-953. [CrossRef]

54. Chok, N.S. Pearson's Versus Spearman's and Kendall's Correlation Coefficients for Continuous Data. Ph.D. Thesis, University of Pittsburgh, Pittsburgh, PA, USA, 2010.

55. Kendall, M.G.; Smith, B.B. The problem of m rankings. Ann. Math. Stat. 1939, 10, 275-287. [CrossRef]

56. Gibbons, J.D. Kendall M. Rank Correlation Methods, 5th ed.; Edward Arnold: London, UK, 1990.

57. Song, L.; Li, Q.; List, G.F.; Deng, Y.; Lu, P. Using an AHP-ISM Based Method to Study the Vulnerability Factors of Urban Rail Transit System. Sustainability 2017, 9, 1065. [CrossRef]

58. Toth, W.; Vacik, H. A comprehensive uncertainty analysis of the analytic hierarchy process methodology applied in the context of environmental decision making. J. Multi-Criteria Decis. Anal. 2018. [CrossRef] 